\title{
Immunohistochemistry on Cell Blocks From Fine- Needle Cytopunctures of Primary Breast Carcinomas and Lymph Node Metastases
}

\author{
Marianne Briffod, M.D., Kamel Hacène, D.Sc., Viviane Le Doussal, M.D. \\ Département d'Anatomie et de Cytologie Pathologiques (MB, VLD) and Département de Statistiques \\ Médicales (KH), Centre René Huguenin de Lutte Contre le Cancer, Saint-Cloud, France
}

We assessed the reliability of prognostic biologic markers by means of immunohistochemistry on cell blocks obtained from diagnostic fine-needle cytopunctures of breast carcinomas and their lymph node metastases.

Immunohistochemical studies of MIB-1 (Ki-67), estrogen receptors (ER), progesterone receptors (PR), p53, and c-erb-B-2 were performed in 55 cases of primary breast carcinoma on cell blocks (cytoblock technique) and on their corresponding tissue samples (46 mastectomy specimens and 9 Trucut biopsies) and in 38 cases on cell blocks from fineneedle cytopunctures of both the primary breast tumors and their concurrent lymph node metastases.

Interobserver reproducibility ranged from 87 to $100 \%$, depending on the marker. A good correlation was observed between immunostaining assessment on cell blocks and on the corresponding tumor tissues as follows: Ki-67 (85\%), ER (96\%), PR (82\%), p53 (76\%), and c-erb-B-2 (84\%). An excellent correlation was observed between cell-block results for primary tumors and node metastases; however, a far higher percentage of Ki-67-positive nuclei was observed in the nodes than in the corresponding tumors in seven cases. All nodes corresponding to ER- or PR-negative tumors were also negative, whereas the nodes corresponding to two ERpositive and one PR-positive tumor were negative. Marked discrepancies were also noted with p53 in two cases and with c-erb-B-2 in two cases. Most discrepancies occurred with Trucut biopsies and with breast tumors that contained a large intraductal component.

Copyright () 2000 by The United States and Canadian Academy of Pathology, Inc.

VOL. 13, NO. 8, P. 841, 2000 Printed in the U.S.A

Date of acceptance: February 8, 2000.

Address reprint requests to: Marianne Briffod, M.D., Service d'Anatomie et de Cytologie Pathologiques, Centre René Huguenin, 35 rue Dailly, 92211 Saint-Cloud, France; e-mail: briffodm@hotmail.com; fax: 330147 111516.
We conclude that cell blocks prepared from fineneedle cytopuncture specimens of breast carcinomas and their node metastases are useful when planning neoadjuvant treatment.

KEY WORDS: Breast cancer, Cell block, Fine-needle cytopuncture, Immunohistochemistry, Lymph node metastasis.

Mod Pathol 2000;13(8):841-850

Major progress has been made in recent years in immunohistochemical detection of various markers (cell proliferation markers, hormone receptors, etc.), improving knowledge and management of breast cancer. Most work reported in the literature has been done on frozen or paraffin-embedded tumor tissues. Fine-needle cytopuncture, which is useful for pretherapeutic diagnosis of breast cancer and for monitoring its progression, often provides highly cellular material representative of the lesions (1-5), which can be used for such analyses. Various studies have shown that nuclear and cytoplasmic markers can be detected individually by means of immunocytochemistry on cytopuncture smears, whereas immunohistochemical studies of cells present in paraffin miniblocks can simultaneously identify several markers on consecutive sections (6). Whatever the technique used, however, the risk of sample contamination by ductal carcinoma in situ (DCIS) is a major problem (7). The aim of this study was to assess the reliability of immunohistochemical detection of markers considered predictive of the prognosis and/or the response to therapy in cytoblock preparations of fine-needle cytopuncture breast cancer specimens.

We tested a series of cytoblocks from 93 patients with primary breast cancer. In 55 cases, we compared marker detection on cytoblocks and on the corresponding tissue samples to determine the reliability and difficulties of cytoblock assessment. In 38 cases, we compared cytoblocks of the mammary tumor and cytoblocks of concurrent metastatic 
nodes, the invasive nature of the mammary carcinoma being provided by nodal involvement.

\section{MATERIALS AND METHODS}

\section{Populations}

Cells were obtained from two groups of patients by means of diagnostic fine-needle cytopuncture, without aspiration. In the first group, consisting of 55 women with primary breast carcinoma $(8 \mathrm{~T} 1,32$ T2, 15 T3), we compared cytoblocks and their corresponding tissue samples (46 mastectomy specimens and 9 Trucut biopsies); node status was available in 50 cases (19 node negative and 31 node positive). The second group consisted of 38 women with primary breast carcinoma $(12 \mathrm{~T} 2,7 \mathrm{~T} 3,3 \mathrm{~T} 4,5$ inflammatory, and 11 initially metastatic) and concurrent node metastases (36 axillary and 2 supraclavicular).

Three cytopunctures were performed on each primary tumor or metastasis. Part of each cytopuncture specimen was smeared for cytologic diagnosis (including cytologic nuclear grading) (7); the material that remained in the needle was ejected into the same tube for fixation in $1 \mathrm{~mL}$ neutral formol for at least $1 \mathrm{~h}$.

The cytoblock technique was performed with the Shandon kit according to the manufacturer's instructions (Shandon Inc., Pittsburgh, PA). We slightly modified the technique by using only one cytocentrifugation step. The button of cells formed was routinely processed and paraffin embedded. Tumor tissues were fixed in neutral formol. Immunohistochemistry was applied to $2.5-\mu \mathrm{m}$ paraffin sections of each specimen.

\section{Immunohistochemistry}

\section{Procedure}

The simultaneous procedure was applied only to cytoblocks from paired tumors and metastatic nodes (38 cases). A microwave antigen-retrieval technique was used in all cases. Sections were mounted on triethylenethiophosphoramideprecoated slides and allowed to dry at $50^{\circ} \mathrm{C}$ overnight. The sections were then dewaxed in xylene and hydrated through graded concentrations of alcohol. Endogenous peroxidase activity was blocked with $1 \%$ hydrogen peroxide for 15 min. Sections were then immersed in a thermoresistant plastic

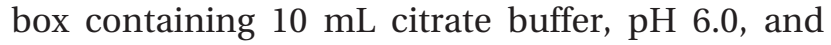
treated in a microwave oven four times at $750 \mathrm{~W}$ for $5 \mathrm{~min}$ each. Sections were allowed to cool at room temperature for $30 \mathrm{~min}$ and were rinsed in Trisbuffered saline. The blocking reagent was tipped away and the primary antibodies were added for $1 \mathrm{~h}$. A standard avidin-biotin-horseradish peroxi- dase complex was used to reveal antibody-antigen reactions. Staining was routinely developed using diaminobenzidine tetrahydrochloride followed with a light hematoxylin counterstain.

Five biologic markers were investigated. The growth fraction was assessed using MIB-1 antibodies that recognize Ki-67 antigen (Immunotech ITS, France) at 1:100 dilution. Hormone receptor expression was assessed with the antiestrogen-receptor antibody Dako-ER 1D5 at 1:30 dilution (Dako SA, Trappes, France) and the antiprogesterone-receptor antibody PR 1A6 at 1:30 dilution (Novocastra Laboratories, Newcastle, UK). P53 protein expression was detected using DO-7 antibody at 1:100 dilution (Dako). C-erb-B-2 oncoprotein expression was detected with a polyclonal antibody at 1:300 dilution (Dako).

\section{Assessment of staining}

The percentage of positive cells was scored for all of the markers. At least 100 malignant cells were considered suitable for immunohistochemistry on cytoblocks. Any nuclei with detectable staining was considered positive for Ki-67. We used a two-group classification (high and low Ki-67 when the proportions of stained nuclei were $\geq 20 \%$ and $<20 \%$, respectively).

Tumors were scored as positive for estrogen receptors (ER), progesterone receptors (PR), and p53 when nuclear staining was identified in at least $10 \%$ of cells and for c-erb-B-2 when definite membrane staining was identified in at least $10 \%$ of cells. Staining for these markers was classified as positive or negative (two-group classification) and also in three groups $(<10 \%, \quad 10$ to $49 \%, \geq 50 \%)$ to analyze strongly positive tumors $(\geq 50 \%)$. With these four markers, we also assessed the intensity of staining as weak $(=1)$, moderate $(=2)$, or strong $(=3)$, and a score was calculated as the percentage of positive cells multiplied by the staining intensity.

\section{Statistical Methods}

The interobserver reproducibility of the cytoblock results was assessed by two independent observers on the 55 tumors in the first group, using the $\kappa$ coefficient to measure the degree of agreement between the two observers. The relationship between the quantitative values obtained on cytoblocks and tumor tissues was analyzed by using a nonparametric test with Spearman's rank coefficient $(r)$.

\section{RESULTS}

Interobserver reproducibility (MB and VLD) on the cytoblocks of the first group, based on the respective cutoffs for the two-group classification, 
was $91 \%$ for Ki-67, $100 \%$ for ER, 93\% for PR and p53, and $87 \%$ for c-erb-B-2. The agreement rate $(\kappa$ coefficient) was 0.81 (Ki-67), 1.00 (ER), 0.83 (PR), 0.84 (p53), and 0.74 (c-erb-B-2). The concordance rate in the three-group classifications was $96 \%$ (ER), $87 \%$ (PR), 84\% (p53), and 80\% (c-erb-B-2).

\section{Comparison Between Immunoresults on Cytoblocks and on Tissue Sections (55 cases)}

Thirty-seven carcinomas were purely invasive, whereas 18 also contained an in situ component. Only the invasive component was taken into account when examining tumor tissues. Comparisons of immunoresults were based on evaluation of markers done by MB on cytoblocks and VLD on tumor tissues.

\section{Comparison of Positive-Cell Percentages Between Cytoblocks and Tissue Specimens}

Median Ki-67 percentages of positive nuclei were $15 \%$ on cytoblocks ( 0 to $60 \%$ ) and $20 \%$ ( 0 to $75 \%$ ) on tissue specimens. The correlation coefficient between quantitative values obtained on cytoblocks and tissue specimens was 0.78 . The same proportion of tumors with high Ki-67 (38\%) was observed in cytoblocks and tissues. The concordance rate was $85.4 \%$ (Table 1 ).

Median ER percentages of positive nuclei were $60 \%$ ( 0 to $100 \%$ ) on cytoblocks and $70 \%$ (0 to $100 \%$ ) on tissue specimens. The correlation coefficient was 0.77 . In the two-group classification, the same percentage of tumors $(81.8 \%)$ was ER positive on cytoblocks and tissue specimens. The concordance rate was $96.3 \%$, compared with $85.5 \%$ in the threegroup classification (Fig. 1). The proportion of highly positive tumors was $69 \%$ on cytoblocks and $76.5 \%$ on tissue specimens. Two cases were clearly discrepant (negative versus highly positive $\geq 50 \%$ ).

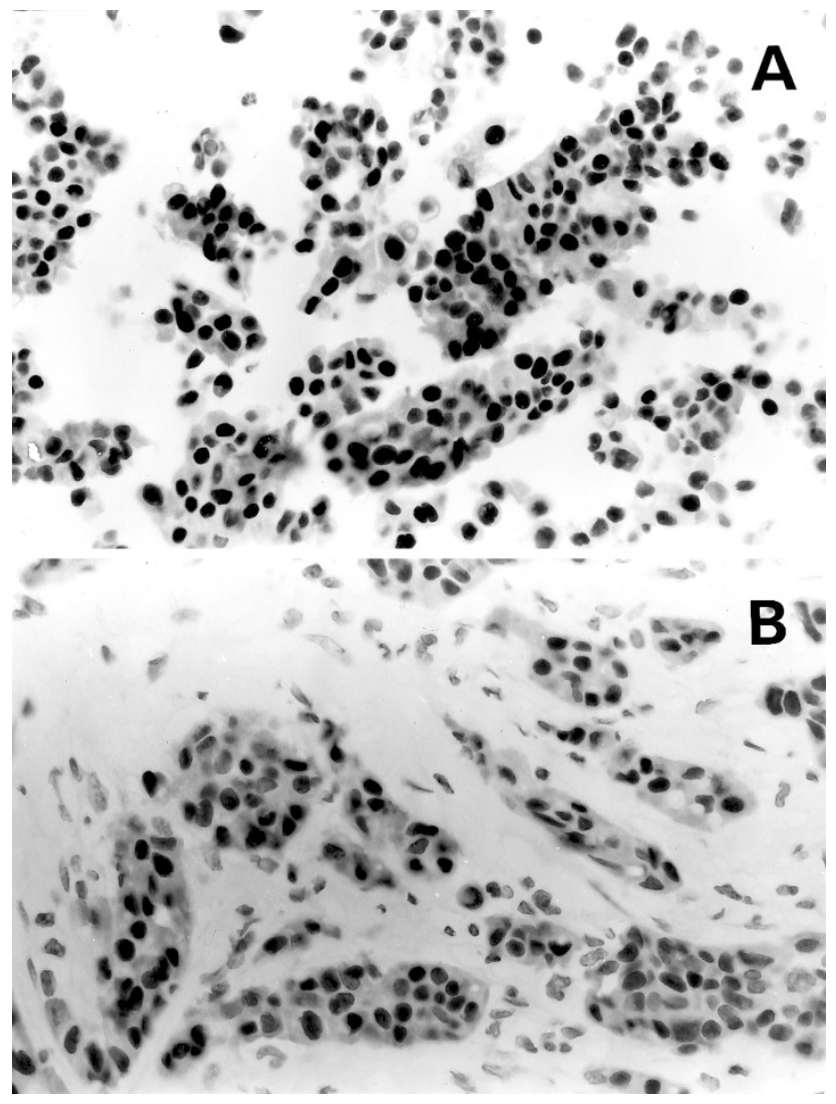

FIGURE 1. A highly positive breast tumor for estrogen receptors on cell block (A) and on tumor tissue specimen $(\mathbf{B})(\times 400)$.

Median PR percentages of positive nuclei were $20 \%$ ( 0 to $95 \%$ ) on cytoblocks and $25 \%$ (0 to 100\%) on tissue specimens. The correlation coefficient was 0.76 . In the two-group classification, 37 cases were PR positive on cytoblocks (67.3\%) and 39 on tissue specimens $(70.9 \%)$. The concordance rate was $81.8 \%$. In the three-group classification, the concordance rate was $70.9 \%$. The proportion of highly positive tumors was $31 \%$ on cytoblocks and

TABLE 1. Ki-67, ER, PR, p53, and c-erb-B-2 Status: Comparison Between Cytoblocks and Tissues

\begin{tabular}{|c|c|c|c|c|c|}
\hline \multirow{2}{*}{ Cytoblocks } & \multirow{2}{*}{ Positive Cells (\%) } & \multicolumn{3}{|c|}{ Tissue Sections $(n=55)$} & \multirow{2}{*}{ Concordance } \\
\hline & & - & + & ++ & \\
\hline $\mathrm{Ki}-67^{-}$ & $<20$ & 30 & 4 & & \\
\hline $\mathrm{Ki}-67^{+}$ & $\geq 20$ & 4 & 17 & & $47 / 55(85.4 \%)^{a}$ \\
\hline $\mathrm{ER}^{-}$ & $<10$ & 9 & 0 & 1 & \\
\hline $\mathrm{ER}^{+}$ & $10-49$ & 0 & 2 & 5 & $53 / 55(96.3 \%)^{a}$ \\
\hline $\mathrm{ER}^{++}$ & $\geq 50$ & 1 & 1 & 36 & $47 / 55(85.5 \%)^{b}$ \\
\hline $\mathrm{PR}^{-}$ & $<10$ & 12 & 5 & 1 & \\
\hline $\mathrm{PR}^{+}$ & $10-49$ & 4 & 10 & 6 & $45 / 55(81.8 \%)^{a}$ \\
\hline $\mathrm{PR}^{++}$ & $\geq 50$ & 0 & 0 & 17 & $39 / 55(70.9 \%)^{b}$ \\
\hline p55 ${ }^{-}$ & $<10$ & 17 & 2 & 0 & \\
\hline p5 $53^{+}$ & $10-49$ & 10 & 13 & 2 & $42 / 55(76.4 \%)^{a}$ \\
\hline $\mathrm{p} 53^{++}$ & $\geq 50$ & 1 & 2 & 8 & $38 / 55(69.1 \%)^{b}$ \\
\hline $\mathrm{c}-e r b-\mathrm{B}-2^{-}$ & $<10$ & 15 & 5 & 4 & \\
\hline c-erb-B-2 ${ }^{+}$ & $10-49$ & 0 & 6 & 7 & $46 / 55(83.6 \%)^{a}$ \\
\hline c-erb-B-2 $2^{++}$ & $\geq 50$ & 0 & 2 & 16 & $37 / 55(67.3 \%)^{b}$ \\
\hline
\end{tabular}

ER, estrogen receptors; PR, progesterone receptors; - , negative; + , positive, ++ , highly positive $(\geq 50 \%)$.

${ }^{a}$ Two-group classification $(-$ versus + and ++ ).

${ }^{b}$ Three-group classification. 
$44 \%$ on tissue specimens, with only one clearly discrepant case.

Median p53 percentages of positive nuclei were $15 \%$ (0 to $100 \%$ ) on cytoblocks and $8 \%$ (0 to $100 \%$ ) on tissue specimens. The correlation coefficient was 0.86 . In the two-group classification, 36 cases (65.4\%) were p53 positive on cytoblocks, compared with $27(49.1 \%)$ on tissue specimens. The concordance rate was $76.4 \%$. In the three-group classification, the concordance rate was $69.1 \%$. The proportion of highly positive tumors was $18 \%$ on cytoblocks and $20 \%$ on tissue specimens, with only one clearly discrepant case.

Median c-erb-B-2 percentages of positive cells were $15 \%$ ( 0 to $100 \%$ ) on cytoblocks and $40 \%$ ( 0 to $100 \%)$ on tissue specimens. The correlation coefficient was 0.79 . In the two-group classification, 31 tumors $(56.4 \%)$ were c-erbB-2 positive on cytoblocks and $40(72.7 \%)$ on tissue specimens. The concordance rate was $83.6 \%$. In the three-group classification, the concordance rate was $67.3 \%$. The percentage of highly positive tumors was $49 \%$ on cytoblocks and $33 \%$ on tissue specimens, with four clearly discrepant cases.

\section{Discrepant Results}

Discrepancies can be due to several causes: (1) poor fixation and/or immunostaining was probably responsible for one case of complete ER negativity on cytoblock, one case of complete PR negativity on tumor tissue, one case of complete p53 negativity on tumor tissue (despite two attempts), and two c-erb-B-2-negative cytoblocks; (2) values close to the cutoff: Ki-67 in two cases, PR in three cases, $p 53$ in four cases, and c-erb-B-2 in one case; (3) weak staining: PR in five cases, p53 in 9 cases, and c-erbB-2 in three cases; (4) assessment on Trucut biop- sies: Ki-67 in two cases, PR in two cases, and p53 in three cases.

Discrepancies were more frequent when the tumor contained a DCIS component than when it was purely invasive (Table 2), as follows: 3 of 18 versus 5 of 37 for Ki-67 (Fig. 2), with large differences in 5 cases (always higher in the tumor than in the cytoblock); 1 of 18 versus 1 of 37 for ER; 5 of 18 versus 5 of 37 for PR; 5 of 18 versus 8 of 37 for p53; and 5 of 18 versus 4 of 37 for c-erb-B-2. Moreover, the correlation coefficients were better in the purely invasive subgroup than in the subgroup with DCIS.

\section{Comparison between cytoblocks and tumor tissues based on intensity score}

The quantitative values obtained by multiplying the percentage of positives cells by the staining intensity showed a fairly good correlation for ER $(r=.63)$ and PR $(r=.69)$ and a good correlation for p53 (0.86) and c-erb-B-2 $(r=.80)$ in the overall group; the correlations were stronger in the purely invasive subgroup $(r=.66, .72, .86$, and .81 , respectively).

Comparison between cytoblocks of primary tumors and cytoblocks of the corresponding concurrent node metastases

We obtained a very good correlation with all the markers between the percentage of positive cells in the primary tumors and the node metastases in the 38 cases ( $r=.86$ to .96 ) (Table 3 ).

Seventy-one percent of the breast tumors and $84 \%$ of the node metastases had high Ki-67 expression, and 31 of 38 cases were concordant (81.6\%). Among the seven discrepant cases, only one had low Ki-67 expression in the metastatic node. Furthermore, in seven cases, there was a clear increase

TABLE 2. Comparison Between Immunohistochemistry Results in Purely Invasive Carcinomas and in Carcinomas Associated with a DCIS Component

\begin{tabular}{|c|c|c|c|c|c|c|c|c|c|}
\hline \multirow{2}{*}{ Cytoblocks } & \multirow{2}{*}{$\begin{array}{l}\text { Positive } \\
\text { Cells (\%) }\end{array}$} & \multicolumn{3}{|c|}{$\begin{array}{l}\text { Purely Invasive } \\
\quad(n=37)\end{array}$} & \multirow{2}{*}{ Concordance } & \multicolumn{3}{|c|}{$\begin{array}{c}\text { Invasive }+ \text { DCIS } \\
(n=18)\end{array}$} & \multirow{2}{*}{ Concordance } \\
\hline & & - & + & ++ & & - & + & ++ & \\
\hline Ki-67- & $<20$ & 19 & 3 & & & 11 & 1 & & \\
\hline $\mathrm{Ki}-67^{+}$ & $\geq 20$ & 2 & 13 & & $32 / 37(86.5 \%)^{a}$ & 2 & 4 & & $15 / 18(83.3 \%)^{a}$ \\
\hline $\mathrm{ER}^{-}$ & $<10$ & 7 & 0 & 1 & & 2 & 0 & 0 & \\
\hline $\mathrm{ER}^{+}$ & $10-49$ & 0 & 1 & 3 & $36 / 37(97.3 \%)^{a}$ & 0 & 1 & 2 & $17 / 18(94.4 \%)^{a}$ \\
\hline $\mathrm{ER}^{++}$ & $\geq 50$ & 0 & 1 & 24 & $32 / 37(86.5 \%)^{b}$ & 1 & 0 & 12 & $15 / 18(83.3 \%)^{b}$ \\
\hline $\mathrm{PR}^{-}$ & $<10$ & 10 & 3 & 1 & & 2 & 2 & 0 & \\
\hline $\mathrm{PR}^{+}$ & $10-49$ & 1 & 6 & 4 & $32 / 37(86.5 \%)^{a}$ & 3 & 4 & 2 & $13 / 18(72.2 \%)^{a}$ \\
\hline $\mathrm{PR}^{++}$ & $\geq 50$ & 0 & 0 & 12 & $28 / 37(75.7 \%)^{b}$ & 0 & 0 & 5 & $11 / 18(61.1 \%)^{b}$ \\
\hline p55 $3^{-}$ & $<10$ & 10 & 1 & 0 & & 7 & 1 & 0 & \\
\hline p53 $3^{+}$ & $10-49$ & 6 & 10 & 1 & $29 / 37(78.4 \%)^{a}$ & 4 & 3 & 1 & $13 / 18(72.2 \%)^{a}$ \\
\hline p5 $53^{++}$ & $\geq 50$ & 1 & 2 & 6 & $26 / 37(70.3 \%)^{b}$ & 0 & 0 & 2 & $12 / 18(66.6 \%)^{b}$ \\
\hline c-erb-B-2- & $<10$ & 11 & 2 & 2 & & 4 & 3 & 2 & \\
\hline c-erb-B-2 $2^{+}$ & $10-49$ & 0 & 4 & 4 & $33 / 37(89.2 \%)^{a}$ & 0 & 2 & 3 & $13 / 18(72.2 \%)^{a}$ \\
\hline c-erb-B-2 $2^{++}$ & $\geq 50$ & 0 & 2 & 12 & $27 / 37(72.9 \%)^{b}$ & 0 & 0 & 4 & $10 / 18(55.5 \%)^{b}$ \\
\hline
\end{tabular}

DCIS, ductal carcinoma in situ; ER, estrogen receptors; PR, progesterone receptors; - , negative; + , positive; ++ , highly positive ( $\geq 50 \%$ ).

$a$ Two-group classification.

${ }^{b}$ Three-group classification. 

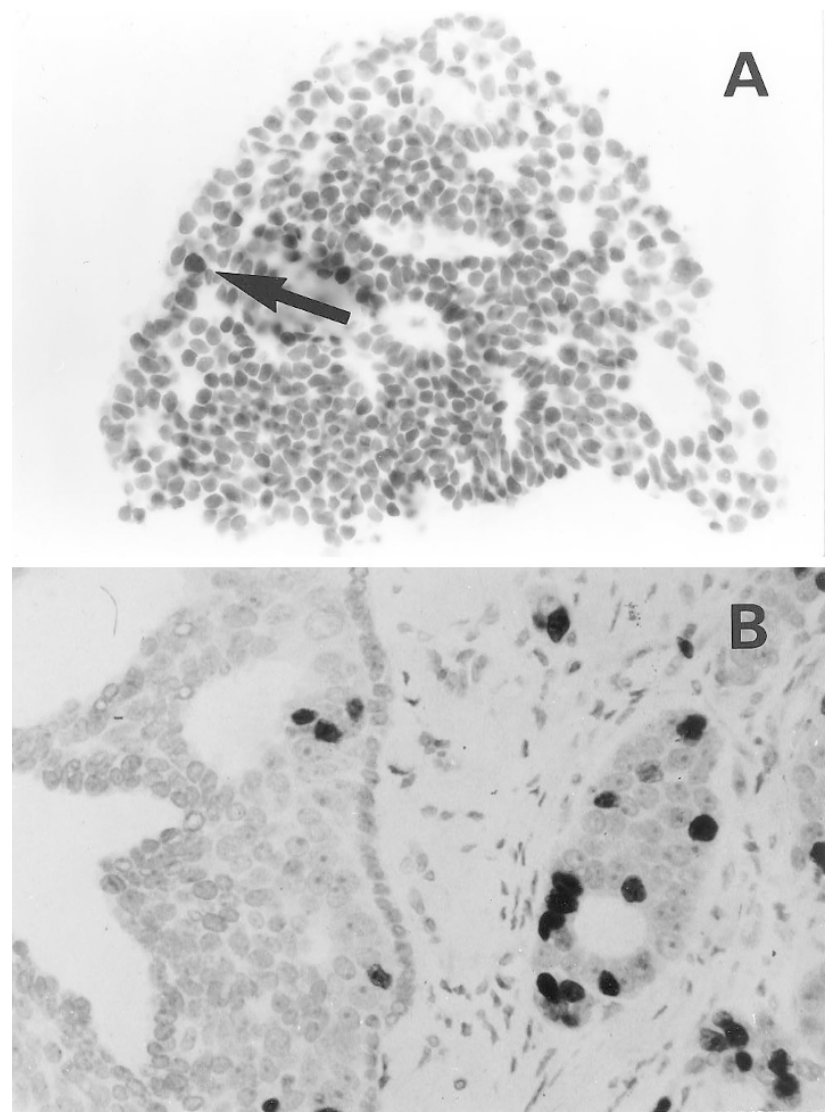

FIGURE 2. A discrepant case for Ki-67. A, on cell block: few positive nuclei (arrow) in cells evocative of the ductal carcinoma in situ component. B, on tumor tissue: with a greater percentage of positive nuclei in the invasive carcinomatous component than in the ductal carcinoma in situ one $(\times 400)$.

in the proportion of stained nuclei in the metastatic node $(>10 \%)$, whereas there was a clear decrease in two cases.

ER status was concordant in 36 cases $(94.7 \%)$, with 28 tumors $(73.7 \%)$ and 26 nodes $(68.4 \%)$ being ER positive. All ER-negative tumors had ERnegative nodes, whereas two ER-positive tumors had ER-negative nodes. Moreover, two strongly ERpositive tumors $(\geq 50 \%$ ) corresponded to a decrease in positive nuclei in nodes, and one weakly labeled ER-positive tumor (12\%) had a strongly labeled node.

PR status concorded in 33 cases (86.8\%). Fifteen tumors $(39.5 \%)$ and 14 nodes $(36.8 \%)$ were PR positive. Twenty-one PR-negative tumors had PRnegative nodes, whereas two PR-negative tumors had PR-positive nodes. Three PR-positive tumors had PR-negative nodes, including two strongly PRpositive tumors that had completely PR-negative nodes (one was a histologically heterogeneous tumor with a large DCIS component). Moreover, two tumors had nodes with far higher percentages of positive nuclei.

P53 status concorded in 35 cases (92\%). Nineteen tumors (50\%) and 20 nodes (52.6\%) were p53 pos- itive. Only one p53-positive tumor had a completely p53-negative node (the mammary tumor had a large DCIS component). Among the p53-negative tumors, 17 had p53-negative nodes and two had p53-positive nodes. Finally, p53 immunopositivity was lower in one node than in the corresponding tumor.

C-erb-B-2 status concorded in 35 cases $(92 \%)$ (Fig. 3). Twenty-eight tumors (73.7\%) and 29 nodes (76.3\%) were c-erb-B-2 positive. Only one positive tumor had a negative node, whereas two c-erb-B2-negative tumors had positive nodes. In one case, the percentage of positive cells was higher in the node than in the tumor, whereas the reverse was true in another case.

A good correlation between the tumors and nodes was observed in regard to the percentage of positive cells multiplied by the intensity score $(r=$ .84 [ER], .89 [PR], .97 [p53], .89 [c-erb-B-2]).

\section{Comparison between the two groups of mammary cytoblocks}

The second group comprised far more tumors with high Ki-67 than the first group (71 versus $38 \%$ ), together with fewer ER-positive tumors (73.7 versus $82 \%$ ), fewer PR-positive tumors (39.5 versus 67\%), fewer p53=positive tumors (50 versus $65 \%$ ), slightly more strongly p53-positive tumors (32 versus $20 \%$ ), more c-erb-B-2-positive tumors (74 versus 56\%), and more strongly c-erb-B-2-positive tumors (58 versus $33 \%$ ).

\section{Correlations among biologic parameters in the 93 mammary cytoblocks}

High Ki-67 was linked to ER and PR negativity and was more weakly linked to p53 positivity (in both the two- and three-group classifications). The three-group classification of p53 showed a very strong negative correlation with ER status and, to a lesser extent, with PR status in the three-group classification, whereas the three-group classification of c-erb-B-2 was weakly linked to PR status (two- and three-group classifications). Finally, ER and PR status (two- and three-group classifications) were very strongly correlated with each other; $73.1 \%$ of tumors were ER positive and PR positive (Table 4).

Correlations among biologic parameters, cytologic nuclear grade, and node status (Table 5)

High Ki-67, ER negativity, and p53 positivity correlated with high nuclear grade (Grade 2). High Ki-67, PR negativity, and c-erb-B-2 positivity correlated with node invasion. The other parameters were not significantly linked to node status.

\section{DISCUSSION}

Fine-needle cytopuncture of breast carcinoma often provides highly cellular material that is rep- 
TABLE 3. Comparison Between Immunohistochemistry Results on Breast Tumor Cytoblocks and Node Cytoblocks (38 Cases)

\begin{tabular}{|c|c|c|c|c|c|}
\hline \multirow{2}{*}{ Breast Cytoblock } & \multirow{2}{*}{ Positive Cells (\%) } & \multicolumn{3}{|c|}{ Node Cytoblock } & \multirow{2}{*}{ Concordance } \\
\hline & & - & + & ++ & \\
\hline $\mathrm{Ki}-67^{-}$ & $<20$ & 5 & 6 & & \\
\hline Ki- $67^{+}$ & $\geq 20$ & 1 & 26 & & $31 / 38(81.6 \%)^{a}$ \\
\hline $\mathrm{ER}^{-}$ & $<10$ & 10 & 0 & 0 & \\
\hline $\mathrm{ER}^{+}$ & $10-49$ & 2 & 2 & 1 & $36 / 38(94.7 \%)^{a}$ \\
\hline $\mathrm{ER}^{++}$ & $\geq 50$ & 0 & 2 & 21 & $33 / 38(86.8 \%)^{b}$ \\
\hline $\mathrm{PR}^{-}$ & $<10$ & 21 & 2 & 0 & \\
\hline $\mathrm{PR}^{+}$ & $10-49$ & 1 & 4 & 2 & $33 / 38(86.8 \%)^{a}$ \\
\hline $\mathrm{PR}^{++}$ & $\geq 50$ & 2 & 0 & 6 & $31 / 38(81.6 \%)^{b}$ \\
\hline p55 ${ }^{-}$ & $<10$ & 17 & 2 & 0 & \\
\hline p53 $3^{+}$ & $10-49$ & 1 & 6 & 0 & $35 / 38(92.1 \%)^{a}$ \\
\hline p53 $3^{++}$ & $\geq 50$ & 0 & 1 & 11 & $34 / 38(89.5 \%)^{b}$ \\
\hline c-erb-B-2 $2^{-}$ & $<10$ & 8 & 2 & 0 & \\
\hline c-erb-B-2 $2^{+}$ & $10-49$ & 1 & 3 & 2 & $35 / 38(92.1 \%)^{a}$ \\
\hline c-erb-B-2 $2^{++}$ & $\geq 50$ & 0 & 1 & 21 & $32 / 38(84.2 \%)^{b}$ \\
\hline
\end{tabular}

ER, estrogen receptors; PR, progesterone receptors; - , negative; + , positive; ++ , highly positive $(\geq 50 \%)$.

$a$ Two-group classification.

${ }^{b}$ Three-group classification.

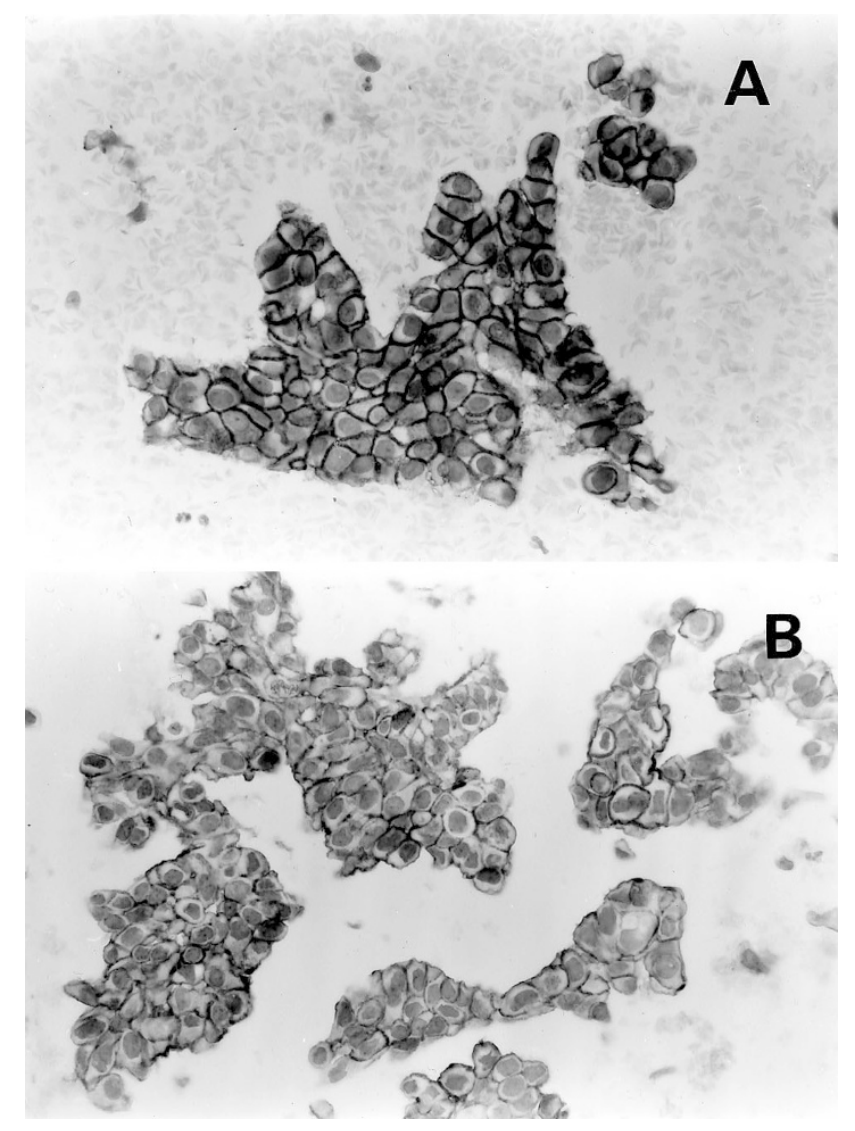

FIGURE 3. A concordant case, highly positive for c-erb-B-2, on cell block from the breast tumor (A) and on cell block from the metastatic axillary node $(B)(\times 400)$.

resentative of the tumors. These samples can be used not only for cytologic diagnosis but also to obtain information on the prognosis and likely response to therapy.

Recent years have seen major technological developments aimed at gleaning the maximum amount of information from this type of sample,
TABLE 4. Relationship Between Biologic Parameters Determined on Breast Cytoblocks from Groups 1 and 2 (93 Cases)

\begin{tabular}{ccl}
\hline Parameters & $\chi^{2}$ & p Value \\
\hline Ki-67 vs. ER & $15.03^{a}$ & $<.001$ \\
& $15.04^{b}$ & $<.0005$ \\
Ki-67 vs. PR & $20.52^{a}$ & $<.00001$ \\
& $20.67^{b}$ & $<.0005$ \\
Ki-67 vs. p53 & $5.61^{a}$ & $<.02$ \\
& $9.89^{b}$ & $<.01$ \\
ER vs. PR & $21.79^{a}$ & $<.00001$ \\
& $25.10^{b}$ & $<.0005$ \\
p53 vs. ER & $4.59^{a}$ & $<.04$ \\
& $23.21^{b}$ & $<.0005$ \\
p53 vs. PR & $10.39^{b}$ & $<.05$ \\
c- $e r b$-B-2 vs. PR & $12.23^{b}$ & $<.02$ \\
\hline
\end{tabular}

ER, estrogen receptors; PR, progesterone receptors.

${ }^{a}$ Two-group classification.

${ }^{b}$ Three-group classification.

through immunocytohistochemistry, image analysis and flow cytometry, and now cytogenetics and molecular biology (1-8).

The possibility of including cells in miniblocks and thereby obtaining multiple sections has been the subject of several reports, but it was Pinder et al. (6) who first studied the value of this method for analyzing multiple prognostic markers by means of immunohistochemistry in breast cancer. Pinder $e t$ al.'s study focused on samples obtained by fineneedle aspiration (FNA) of resected tumors, whereas we worked exclusively on samples obtained before therapy by in vivo cytopuncture, when cellularity of the sample was obvious. Consequently, we did not seek to determine what proportion of breast cancers would yield useable cytoblocks. We used Pinder et al.'s technique with slight modifications. To evaluate the reliability of the method and to identify possible sources of error in the assessment of the different immunomarkers on cytoblocks of the primary breast tumor, we com- 


\begin{tabular}{|c|c|c|c|c|c|c|c|}
\hline \multirow[b]{2}{*}{ Cytoblocks } & \multirow{2}{*}{$\begin{array}{l}\text { Positive } \\
\text { Cells (\%) }\end{array}$} & \multicolumn{3}{|c|}{ Cytologic Nuclear Grade $(n=79)$} & \multicolumn{3}{|c|}{ Nodal Status $(n=88)$} \\
\hline & & $\begin{array}{l}\text { Grade } 1 \\
(n=21)\end{array}$ & $\begin{array}{l}\text { Grade } 2 \\
(n=58)\end{array}$ & $p$ & $\begin{array}{c}\mathrm{N}^{-} \\
(n=19)\end{array}$ & $\begin{array}{c}\mathrm{N}^{+} \\
(n=69)\end{array}$ & $p$ \\
\hline \multirow[t]{3}{*}{ Ki-67 } & $<20$ & 18 & 16 & & 15 & 26 & \\
\hline & $\geq 20$ & 3 & 42 & $<.00001$ & 4 & 43 & $<.01$ \\
\hline & $<10$ & 1 & 18 & & 2 & 18 & \\
\hline \multirow[t]{3}{*}{ ER } & $10-49$ & 1 & 10 & $<.02^{a}$ & 1 & 11 & $\mathrm{NS}^{a}$ \\
\hline & $\geq 50$ & 19 & 30 & $<.01^{b}$ & 16 & 40 & $\mathrm{NS}^{b}$ \\
\hline & $<10$ & 7 & 32 & & 4 & 36 & \\
\hline \multirow[t]{3}{*}{ PR } & $10-49$ & 5 & 15 & $\mathrm{NS}^{a}$ & 8 & 17 & $<.02^{a}$ \\
\hline & $\geq 50$ & 9 & 11 & $\mathrm{NS}^{b}$ & 7 & 16 & $\mathrm{NS}^{b}$ \\
\hline & $<10$ & 12 & 18 & & 6 & 29 & \\
\hline \multirow[t]{3}{*}{ p53 } & $10-49$ & 7 & 19 & $<.04^{a}$ & 10 & 20 & $\mathrm{NS}^{a}$ \\
\hline & $\geq 50$ & 2 & 21 & $<.05^{b}$ & 3 & 20 & $\mathrm{NS}^{b}$ \\
\hline & $<10$ & 9 & 18 & & 12 & 9 & \\
\hline \multirow[t]{2}{*}{ c-erb-B-2 } & $10-49$ & 3 & 10 & $\mathrm{NS}^{a}$ & 4 & 13 & $<.01^{a}$ \\
\hline & $\geq 50$ & 9 & 30 & $\mathrm{NS}^{b}$ & 3 & 37 & $<.01^{a}$ \\
\hline
\end{tabular}

ER, estrogen receptors; PR, progesterone receptors; NS, not significant.

$a$ Two-group classification.

${ }^{b}$ Three-group classification.

pared our breast cytoblock findings with those obtained on the corresponding tissues specimens or on the concomitant node metastases when sampled.

Overall, cytoblock immunostaining was of good quality and free of artifacts such as excessive background. However, cytoplasmic positivity for hormone receptors hindered interpretation in one case with ER and in six cases with PR on the cytoblock of the primary tumor; similar positivity was always found on the corresponding tumor tissue sample or on the cytoblock of the metastatic node. These cases of cytoplasmic positivity seemed to be linked to the nature of the tumor tissue.

The good interobserver reproducibility observed here reflects the quality of the immunostaining and the simplicity of the interpretation; however, c-erbB-2 membrane staining was a little more difficult to interpret than nuclear staining, leading to less good reproducibility ( $87 \%$ versus 91 to $100 \%$ ).

Depending on the marker, a correlation of 76 to 96\% was observed between the cytoblocks and the corresponding tumor tissues in the two-group classifications (negative versus positive). Makris et al. (3) obtained a similar level of agreement for ER, PR, and p53 by means of immunocytochemistry on multiple slides of FNA material after cytocentrifugation. Our correlations were a little less satisfactory in the three-group classification, which individualizes strong positivity. When we used a score taking intensity into account, a very good correlation was obtained with p53 and c-erb-B-2 $(r=.86$ and .80).

In addition to technical problems (which cannot always be overcome, especially on small samples) and more conventional problems such as intra- and interobserver variability, the discrepancies we observed were linked to weak staining and values close to the cutoff; in addition, small samples (cytoblocks and microbiopsies) may not be representative of heterogeneous breast tumors. The impact of tumor heterogeneity, especially when an in situ component is combined with the invasive component (nearly one third of our cases), emerged clearly in this series, as the percentage concordance and correlation coefficients were always better in the purely invasive tumor subgroup than in the subgroup of tumors with a DCIS component.

It is difficult to compare our results with previously published data, because the antibodies, cutoffs, immunostaining assessment (taking into account or not staining intensity), the number of subgroups, and also the study populations vary widely from one report to another.

Positivity cutoffs for Ki-67 range from 10 to 25\%, and the percentage of tumors with high Ki-67 range from 26 to $85 \%$, according to the authors (2, 9-13). According to Clahsen et al. (10) and on the basis of two personal studies (unpublished data), one comparing the corresponding values of Ki-67 and SPF, the other studying the prognostic value of SPF in a series of breast carcinoma, we have chosen a cutoff of 20 . With this cutoff, we found that $38 \%$ tumors had high Ki-67 on both cytoblocks and tissue sections.

With p53, the reported cutoffs range from 1 to $75 \%(2,9,10,13-19)$ and the proportion of positive tumors from 14 to $60 \%$. Pinder et al., applying a cutoff of 5 to cytoblocks, obtained $46 \%$ of positive tumors. Six studies with a cutoff of 10 (15), showed a proportion of positive tumors ranging from 16 to $51 \%$. Our histologic results for p53 are within this range, whereas the value obtained on cytoblock was higher (65\%), despite the absence of values between 5 and $10 \%$. However, our percentage of 
strongly positive tumors $(20 \%)$ is comparable to that reported elsewhere $(2,13,20)$.

The c-erb-B-2 cutoff is usually 1 or 5 . An extensive review of the literature (21) showed that 10 to $34 \%$ of breast cancers had HER-2/ neu gene amplification or c-erb-B-2 protein overexpression when examined immunohistochemically. Pinder et al., using a cutoff of 1 , found $38 \%$ of positive tumors on cytoblocks. Our percentage of positive tumors was higher on cytoblocks (56\%) and even more so on tumor tissues $(73 \%)$, possibly owing to the sensitivity of the antibodies at the dilution used or to the composition of our population (56\% of nodepositive tumors). However, Solomides et al. (5) recently found percentages similar to ours in their study of cytology specimens. Finally, the percentage of highly positive tumors in our study (33\%) is higher than that reported by Rozan et al. (13) but close to that of Berger et al. (22).

Comparisons of hormone receptors are easier, because they are better studied and coded, with well-established comparisons with biologic assays (23, 24) and clinical features (25-27). Although, once again, there is no international consensus on cutoff values, several authors recommend a value of $10 \%$ positive nuclei $(1,27-29)$, without taking labeling intensity into account. The percentages of ERpositive tumors $(82 \%$ on cytoblocks and tissues) and PR-positive tumors $(67 \%$ on cytoblocks and $71 \%$ on tissues) are in keeping with those generally observed in the literature, whether the percentages of positive nuclei are considered alone (1) or combined with staining intensity $(3,4,30,31)$, if one considers the median age of our patients (60 years).

An excellent correlation was observed in the second group between cytoblock immunostaining of the breast tumor and of the corresponding metastatic node. This type of comparison is rare. Bhargava et al. (32), in their series of 24 invasive primary breast cancers with node metastases, observed full concordance on histologic sections between p53 immunopositivity of the primary tumor and metastatic node, and Barnes et al. (33) obtained similar results for c-erb-B-2. These data suggest that the metastatic cell population is very similar to the invasive breast tumor cell population, in keeping with studies based on flow cytometry $(34,35)$ and molecular biology $(36,37)$. Certain conflicting results in our series can be linked to the presence of a DCIS component (e.g., explaining why Ki-67 labeling was more often higher in the metastases than in the corresponding primary tumors $[84 \%$ versus $71 \%$ ]) or to genetic alterations occurring in some cases during the metastatic process, as shown by means of comparative genomic hybridization (38).

Overexpression of proteins related to proliferative activity and c-erb-B-2 oncoprotein, which was more frequent in the primary tumors of the second than of the first group, and the opposite trend in hormone receptors is probably linked to the presence of several very aggressive tumors (inflammatory and initially metastatic) in our series.

Correlations between the various biologic parameters in the mammary cytoblocks are in keeping with those frequently described by other authors. As reported by others $(1,39), \mathrm{Ki}-67$ was significantly linked to p53, and these two markers correlated negatively with ER and PR status $(3,39,40)$. As in all previous studies, ER and PR were very significantly linked; $73 \%$ of tumors were ER positive and PR positive, a proportion close to that obtained by Sauer et al. (4) by immunocytochemistry on FNA slides. Finally, c-erb-B-2 was not linked to any of the other markers, except for a negative correlation with PR also found by other authors $(39,41)$.

As expected, the markers of cell proliferation Ki-67 and p53 were significantly linked to our cytologic nuclear grade, whereas ER correlated negatively with nuclear grade.

In our study, node invasion correlated with high Ki-67 expression, PR negativity, and c-erb-B-2 positivity. Ki-67 labeling was high in $62 \%$ of nodepositive tumors and in only $21 \%$ of node-negative tumors, the latter result being close to that obtained by Dettmar et al. (42). The proportion of ERpositive tumors ranged from 89 to $74 \%$ and that of PR-positive tumors from 79 to $48 \%$ according to node status, but, contrary to Bozetti et al. (1), we found that only PR was significantly linked to node status.

A correlation between c-erb-B-2 overexpression and node status was found here, as by Berger $\mathrm{et} \mathrm{al}$. (22), but not by other authors $(39,41)$. This correlation was found also for highly positive tumors $(\geq 50 \%$ ), which were more numerous in the nodepositive (54\%) than in the node-negative (16\%) population. Once again, the proportion of nodepositive tumors that were strongly positive was far higher than that found by Thor et al. (43). Although p53 did not seem to be significantly linked to node status in our study, highly p53-positive tumors were more numerous in the node-positive $(29 \%)$ that in the node-negative $(16 \%)$ population.

These results suggest that despite the imperfections inherent to this technique, the need to obtain highly cellular samples, and the problem of tumor heterogeneity, cytoblocks can be a useful alternative for marker detection, especially for inoperable carcinoma or when neoadjuvant treatment is planned. Moreover, the coherence of the results obtained here demonstrates that useful information can be obtained on metastatic cell populations not only for diagnostic purposes (samples no longer being contaminated by a DCIS component) but also in the research setting. 
Finally, aggressive tumors with a poor prognosis, especially those with node involvement, clearly overexpressed proteins related to proliferative activity and oncoproteins.

Acknowledgments: The authors thank Odile Champy, Claudine Le Ray, and Catherine Regnier for their excellent technical assistance.

\section{REFERENCES}

1. Bozzetti C, Nizzoli R, Naldi N, Manotti L, Savoldi L, Camisa $\mathrm{R}$, et al. Fine-needle aspiration technique for the concurrent immunocytochemical evaluation of multiple biologic parameters in primary breast carcinoma. Breast Cancer Res Treat 1994;32:221-8.

2. Lavarino C, Corletto V, Mezzelani A, Della Torre G, Bartoli C, Riva C, et al. Detection of TP53 mutation, loss of heterozygosity and DNA content in fine-needle aspirates of breast carcinoma. Br J Cancer 1998;77:125-30.

3. Makris A, Allred DC, Powles TJ, Dowsett M, Fernando IN, Trott PA, et al. Cytological evaluation of biological prognostic markers from primary breast carcinomas. Breast Cancer Res Treat 1997;44:65-74.

4. Sauer T, Beraki E, Jebsen P, Amlie E, Harbitz T, Karesen R, et al. Assessing estrogen and progesterone receptor status in fine-needle aspirates from breast carcinomas. Results on six years of material and correlation with biochemical assay. Anal Quant Cytol Histol 1998;20:122-6.

5. Solomides CC, Zimmerman R, Bibbo M. Semiquantitative assessment of c-erbB-2 (HER-2) status in cytology specimens and tissue sections from breast carcinoma. Anal Quant Cytol Histol 1999;21:121-5.

6. Pinder SE, Wencyk PM, Naylor HE, Bell JA, Elston CW, Robertson JFR, et al. The assessment of multiple variables on breast carcinoma fine needle aspiration (FNA) cytology specimens: method, preliminary results and prognostic associations. Cytopathology 1995;6:316-24.

7. Briffod M, Le Doussal V, Spyratos F. Cytologic nuclear grading of fine-needle cytopunctures of breast carcinoma: comparison with histologic nuclear grading (MSBR) and image cytometric data. Anal Quant Cytol Histol 1997;19:114-22.

8. Fernando IN, Allan SM, Sandle J, Dean C, Sacks N, Trott PA. Immunocytochemical staining for the c-erbB-2 gene product in breast aspirates: a preliminary report. Cytopathology 1993;4:219-24.

9. Archer SG, Eliopoulos A, Spandidos D, Barnes D, Ellis IO, Blamey RW, et al. Expression of ras p21, p53 and c-erbB-2 in advanced breast cancer and response to first line hormonal therapy. Br J Cancer 1995;72:1259-66.

10. Clahsen PC, van de Velde CJH, Duval C, Pallud C, Mandard AM, Delobelle-Deroide A, et al. p53 protein accumulation and response to adjuvant chemotherapy in premenopausal women with node-negative early breast cancer. J Clin Oncol 1998;16:470-9.

11. Jacquemier J, Molès JP, Penault-Llorca F, Adélaide J, Torrente $\mathrm{M}$, Viens $\mathrm{P}$, et al. p53 immunohistochemical analysis in breast cancer with four monoclonal antibodies: comparison of staining and PCR-SSCP results. Br J Cancer 1994;69:84652.

12. MacGrogan G, Jollet I, Huet S, Sierankowski G, Picot V, Bonichon $\mathrm{F}$, et al. Comparison of quantitative and semiquantitative methods of assessing MIB-1 with the S-phase fraction in breast carcinoma. Mod Pathol 1997;10:769-76.

13. Rozan S, Vincent-Salomon A, Zafrani B, Validire P, de Cremoux $\mathrm{P}$, Bernoux A, et al. No significant predictive value of c-erbB-2 or p53 expression regarding sensitivity to primary chemotherapy or radiotherapy in breast cancer. Int J Cancer 1998;79:27-33.

14. Allred DC, Clark GM, Elledge R, Fuqua SAW, Brown RW, Chamness GC, et al. Association of p53 protein expression with tumor cell proliferation rate and clinical outcome in node-negative breast cancer. J Natl Cancer Inst 1993;85: 200-6.

15. Barbareschi M. Prognostic value of immunohistochemical expression of p53 in breast carcinomas. A review of the literature involving over 9,000 patients. Appl Immunohistochem 1996;4:106-16.

16. MacGrogan G, Bonichon F, de Mascarel I, Trojani M, Durand M, Avril A, et al. Prognostic value of p53 in breast invasive ductal carcinoma: an immunohistochemical study on 942 cases. Breast Cancer Res Treat 1995;36:71-81.

17. Moll UM, Ostermeyer AG, Ahomadegbe JC, Mathieu MC, Riou G. p53 mediated tumor cell response to chemotherapeutic DNA damage. A preliminary study in matched pairs of breast cancer biopsies. Hum Pathol 1995;26:1293-301.

18. Silvestrini R, Benini E, Veneroni S, Daidone MG, Tomasic G, Squicciarini $\mathrm{P}$, et al. p53 and bcl-2 expression correlates with clinical outcome in a series of node-positive breast cancer patients. J Clin Oncol 1996;14:1604-10.

19. Silvestrini R, Daidone MG, Benini E, Faranda A, Tomasic G, Boracchi $\mathrm{P}$, et al. Validation of p53 accumulation as a predictor of distant metastasis at 10 years of follow-up in 1400 node-negative breast cancers. Clin Cancer Res 1996;2:200713.

20. Barnes DM, Dublin EA, Fischer CJ, Levison DA, Millis RR. Immunohistochemical detection of p53 protein in mammary carcinoma: an important new independent indicator of prognosis? Hum Pathol 1993;24:469-76.

21. Ross JS, Fletcher JA. The HER-2/neu oncogene in breast cancer. Prognostic factor, predictive factor, and target for therapy. Oncologist 1998;3:237-52.

22. Berger MS, Locher GW, Saurer S, Gullick WJ, Waterfield MD, Groner N, et al. Correlation of cerbB-2 gene amplification and protein expression in human breast carcinoma with nodal status and nuclear grading. Cancer Res 1988;48:122843.

23. Flowers JL, Burton GV, Cox EB, McCarty KS Sr, Dent GA, Geisinger KR, et al. Use of monoclonal antiestrogen receptor antibody to evaluate estrogen receptor content in fine needle aspiration breast biopsies. Ann Surg 1986;203:250-4.

24. Masood S. Use of monoclonal antibody for assessment of estrogen receptor content in fine-needle aspiration biopsy specimen from patients with breast cancer. Arch Pathol Lab Med 1989;113:26-30.

25. Reiner A, Neumeister B, Spona J, Reiner G, Schemper M, Jakesz R. Immunocytochemical localization of estrogen and progesterone receptor and prognosis in human primary breast cancer. Cancer Res 1990;50:7057-61.

26. Barnes DM, Harris WH, Smith P, Millis RR, Rubens RD. Immunohistochemical determination of oestrogen receptor: comparison of different methods of assessment of staining and correlation with clinical outcome of breast cancer patients. Br J Cancer 1996;74:1445-51.

27. Blomqvist C, Von Boguslawski K, Stenman UH, Mäenpää $H$, Von Smitten K, Nordling S. Long-term prognostic impact of immunohistochemical estrogen receptor determinations compared with biochemical receptor determination in primary breast cancer. Acta Oncol 1997;36:530-2.

28. Balaton AJ, Coindre JM, Collin F, Ettore F, Fiche M, Jacquemier J, et al. Recommandations pour l'évaluation immunohistochimiques des récepteurs hormonaux sur coupes en paraffine dans les carcinomes mammaires. Ann Pathol 1996; 16:144-8. 
29. Soubeyran I, Quénel N, Mauriac L, Bonichon F, Coindre JM. Variations of hormonal receptor, pS2, C-erbB-2 and GST $\pi$ contents in breast carcinomas under tamoxifen: a study of 74 cases. Br J Cancer 1996;73:735-43.

30. Reiner A, Spona J, Reiner G, Schemper M, Kolb R, Kwasny W, et al. Estrogen receptor analysis on biopsies and fine-needle aspirates from human breast carcinoma. Correlation of biochemical and immunohistochemical methods using monoclonal antireceptor antibodies. Am J Pathol 1986;125:443-9.

31. Katz RL, Patel S, Sneige N, Fritsche HA, Hortobagyi GN, Ames FC, et al. Comparison of immunocytochemical and biochemical assays for estrogen receptor in fine needle aspirates and histologic sections from breast carcinomas. Breast Cancer Res Treat 1990;15:191-203.

32. Bhargava V, Thor A, Deng G, Ljung BM, Moore DH, Waldman $\mathrm{F}$, et al. The association of p53 immunopositivity with tumor proliferation and other prognostic indicators in breast cancer. Mod Pathol 1994;7: 361-8.

33. Barnes DM, Lammie GA, Millis RR, Gullick WL, Allen DS, Altman DG. An immunohistochemical evaluation of c-erbB-2 expression in human breast carcinoma. Br J Cancer 1988;58:448-52.

34. Feichter GE, Kaufmann M, Muller A, Haag D, Eckhardt R, Goerttler K. DNA index and cell cycle analysis of primary breast cancer and synchronous axillary lymph node metastases. Breast Cancer Res Treat 1989;13:17-22.

35. Goodson WH, Ljung BM, Moore DH, Mayall B, Waldman FM, Chew K, et al. Tumor labeling indices of primary breast cancers and their regional lymph node metastases. Cancer 1993;71:3914-9.

36. Bonsing BA, Devilee P, Cleton-Jansen AM, KuipersDijkshoorn N, Fleuren GJ, Cornelisse CJ. Evidence for limited molecular genetic heterogeneity as defined by allelotyping and clonal analysis in nine metastatic breast carcinomas. Cancer Res 1993;53:3804-11.

37. Chen L, Kurisu W, Ljung B, Goldman E, Moore D, Smith H. Heterogeneity for allelic loss in human breast cancer. J Natl Cancer Inst 1992;84:506-10.

38. Nishizaki T, De Vries S, Chew K, Goodson WH, Ljung BM, Thor A, et al. Genetic alterations in primary breast cancers and their metastases: direct comparison using modified comparative genomic hybridization. Genes Chromosomes Cancer 1997;19:267-72.

39. Sirvent JJ, Salvado MT, Santafé M, Martinez S, Brunet J, Alvaro T, et al. p53 in breast cancer. Its relation to histological grade, lymph-node status, hormone receptors, cellproliferation fraction (Ki-67) and c-erbB-2. Immunohistochemical study of 153 cases. Histol Histopathol 1995; 10: 531-9.

40. Thor AD, Moore DH II, Edgerton SM, Kawasaki ES, Reihsaus E, Lynch SM, et al. Accumulation of p53 suppressor gene protein: an independent marker of prognosis in breast cancers. J Natl Cancer Inst 1992;84:845-55.

41. Battifora H, Gaffrey M, Esteban J, Mehta P, Bailey A, Faucett $\mathrm{C}$, et al. Immunohistochemical assay of neu/c-erbB-2 oncogene product in paraffin-embedded tissues in early breast cancer: retrospective follow-up study of 245 stage I and II cases. Mod Pathol 1991;4:466-74.

42. Dettmar P, Harbeck N, Thomssen C, Pache L, Ziffer P, Fizi K, et al. Prognostic impact of proliferation-associated factors MIB1 (Ki67) and S-phase in node-negative breast cancer. Br J Cancer 1997;75:1525-33.

43. Thor AD, Berry DA, Budman DR, Muss HB, Kute T, Henderson I, et al. erbB-2, p53, and efficacy of adjuvant therapy in lymph node-positive breast cancer. J Natl Cancer Inst 1998; 90:1346-60. 